\title{
Outbreak of hospital-acquired gastroenteritis and invasive infection caused by Listeria monocytogenes, Finland, 2012
}

\author{
A. JACKS ${ }^{1,2}$, A. PIHLAJASAARI ${ }^{3}$, M. VAHE ${ }^{4}$ A. MYNTTI ${ }^{5}$, \\ S.-S. KAUKORANTA ${ }^{6}$, N. ELOMAA ${ }^{1}$, S. SALMENLINNA ${ }^{2}$,

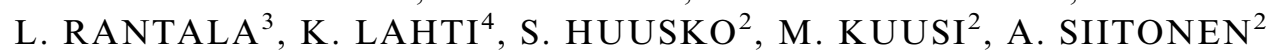 \\ AND R. RIMHANEN-FINNE ${ }^{2 *}$ \\ ${ }^{1}$ Infectious Diseases Unit, Vaasa Central Hospital, Vaasa, Finland \\ ${ }^{2}$ National Institute for Health and Welfare, Helsinki, Finland \\ ${ }^{3}$ Finnish Food Safety Authority Evira, Helsinki, Finland \\ ${ }^{4}$ Vaasa Municipal Hospital, City of Vaasa, Finland \\ ${ }^{5}$ Vaasa, Environment Centre, City of Vaasa, Finland \\ ${ }^{6}$ Department of Clinical Microbiology, Vaasa Central Hospital, Vaasa, Finland
}

Received 8 April 2015; Final revision 2 September 2015; Accepted 30 September 2015; first published online 23 October 2015

\section{SUMMARY}

During one week in July 2012, two patients from the same ward at the municipal hospital in Vaasa, Finland, were diagnosed with septicaemia caused by Listeria monocytogenes. An outbreak investigation revealed eight concomitant cases of febrile gastroenteritis caused by L. monocytogenes on the same ward. Median age of the cases was 82 years and median incubation time for listerial gastroenteritis was $21 \mathrm{~h}$ (range 9-107). An additional 10 cases of invasive listeriosis caused by the same outbreak strain were identified across the whole country during the summer of 2012.

Environmental investigation at the affected municipal hospital ward revealed ready-sliced meat jelly as the suspected source of the infection. During inspection of the meat jelly production plant, one pooled sample taken from a floor drain and a trolley wheel in the food processing environment was positive for the outbreak strain of L. monocytogenes. After the producer stopped the production of meat jelly, no further cases of listeriosis with the outbreak strain were identified via nationwide surveillance.

Key words: Foodborne outbreak, immunosuppression, Listeria monocytogenes, listerial gastroenteritis, nosocomial infection.

\section{INTRODUCTION}

Listeria monocytogenes is a psychrotrophic foodborne pathogen causing invasive disease associated with a high case-fatality rate in immunocompromised patients and in fetuses and neonates [1,2]. During the past 20

\footnotetext{
* Author for correspondence: Dr R. Rimhanen-Finne, National Institute for Health and Welfare, Helsinki, Finland. (Email: ruska.rimhanen-finne@thl.fi)
}

years, L. monocytogenes has been recognized as the causative agent of febrile gastroenteritis in previously healthy individuals [3,4]. Listerial gastroenteritis is distinct from invasive listeriosis in terms of incubation period, symptoms and mortality [5].

In Finland, three outbreaks caused by L. monocytogenes have been described in the past two decades. In 1998, five persons without underlying diseases developed self-limited febrile gastroenteritis; indistinguishable L. monocytogenes were isolated from two stool samples 
from the patients and from cold-smoked rainbow trout that they had consumed [6]. A large hospital outbreak occurred in 1999 causing six deaths in 25 cases of invasive listeriosis; the source of the outbreak, butter, may have been contaminated in the production environment after pasteurization [7]. In 2006, L. monocytogenes was isolated from home-made salted mushrooms that were connected to listeriosis-like symptoms in 11 of 30 persons attending a birthday party [8].

In the period 2000-2009, 18-46 cases of invasive listeriosis were reported to the National Infectious Diseases Register (NIDR) annually in Finland. In 2010, the annual number of reported cases rose to 71 and in the subsequent year, 44 cases were reported [9]. National surveillance does not cover gastroenteritis caused by L. monocytogenes.

In the course of two subsequent days in July 2012, two cases of invasive listeriosis caused by L. monocytogenes serogroup IIa were detected on the same ward unit of a municipal hospital in Vaasa, western Finland. An outbreak investigation was initiated in order to identify the source of infection and to prevent further cases.

\section{MATERIALS AND METHODS}

\section{Case-finding at the hospital}

The municipal hospital in the town of Vaasa in western Finland has 13 wards that are all served with warm meals, lunch, and dinner from a central kitchen. Each ward is equipped with its own kitchen providing breakfast and snacks, with all food items ordered through the catering service of the central kitchen. On 23 and 24 July 2012, two cases of septicaemia caused by $L$. monocytogenes were diagnosed on a ward offering rehabilitative care in orthopaedic surgery and internal medicine. In July 2012, 21 patients (median age 82 years, 11 males, 10 females) were treated on the affected 22-bed ward. In order to detect other cases, the attending physician requested blood cultures from all patients on the ward presenting with fever $\left(>38.0^{\circ} \mathrm{C}\right)$ or other septic symptoms, as well as stool samples for the detection of $L$. monocytogenes. If symptoms were present in the central nervous system (e.g. unconsciousness or altered mental state), lumbar puncture was performed for biochemical ascertainment of meningitis and acquisition of cerebrospinal fluid (CSF) for bacterial culture.

The local outbreak investigation team consisted of the chief physician of the municipal hospital, the attending physician, the chief nurse of the hospital, the municipal food safety inspector and the infection control nurse, and the infectious diseases consultant of the hospital district. Patients with fever or gastrointestinal illness of unknown aetiology from other wards of the hospital were reported on a bi-weekly basis to the local outbreak investigation team.

\section{Clinical microbiological methods}

Blood culture samples were collected in BacT/Alert FAN aerobic and standard anaerobic bottles and incubated in the BacT/Alert 3D automated continuous growth monitoring system (bioMérieux, France). If Gram-positive rods were detected, broth was streaked onto blood and chocolate agar plates, as well as on bile esculin plates. Biochemical identification was performed with the RapID CB Plus system (Thermo Fisher Scientific, USA), and the rapid ID32 STREP v. 3.0 system (bioMérieux, France). In both patients diagnosed with bacteraemia, the identification systems gave phenotypic profiles that referred to the genus Listeria. The isolated strains were sent to the Bacteriology Unit at the National Institute for Health and Welfare (THL) for further characterization.

CSF samples from patients with symptoms from the central nervous system were cultivated on chocolate agar and blood agar plates and incubated for $48 \mathrm{~h}$ at $35^{\circ} \mathrm{C}$ in air supplemented with $5 \% \mathrm{CO}_{2}$.

Before the gastrointestinal illness could be attributed to L. monocytogenes, stool samples from patients with diarrhoeal symptoms were cultivated on selective agar plates in order to detect growth of Salmonella, Shigella, Campylobacter, Yersinia and Clostridium difficile. Stool specimens were also analysed for $C$. difficile toxins, rotavirus, and adenovirus by immunoassays, for norovirus by polymerase chain reaction (PCR) testing, and examined microscopically for detection of intestinal parasites. In the event of bloody diarrhoea, stool samples were analysed for enterohaemorrhagic Escherichia coli. Finally, faecal samples from all patients presenting with diarrhoea were cultivated directly or via enrichment broth (Oxoid SR141) on Palcam selective plates (Merck KGaA, Germany). After a minimum of 2 days' incubation, suspected colonies differentiated by esculin hydrolysis and mannitol fermentation were confirmed as $L$. monocytogenes by using Gram stain, the catalase test, and the VITEK 2 Gram-positive (GP) identification card (bioMérieux) and were thereafter sent to the Bacteriology Unit at THL. 


\section{Environmental investigation}

Between 30 July and 1 August 2012, the municipal food safety authority inspected the central kitchen of the municipal hospital as well as the kitchen facility on the outbreak ward. Details of all meals served during the 3 weeks preceding the onset of symptoms of the first cases as well as a list of food items delivered directly to the wards for breakfast and snack services were obtained. Food samples from all meals served during the week preceding the onset of symptoms of the first cases were collected together with 19 environmental samples (condensation water from refrigerators and the ventilation system, food processing surfaces, drinking water) from the central and the ward kitchens, and sent to the local environmental laboratory for detection of $L$. monocytogenes.

Foods that were considered risk items for Listeria transmission in a hospital environment included coldcut meats, cold prepared salads, soft cheeses and other dairy-based products [10], and were sampled and sent to the local environmental laboratory for detection of L. monocytogenes. All food and environmental samples were analysed in accordance with ISO 11290-1/ A1-2004 standards.

The processing facility producing the suspected source of the outbreak, meat jelly, was inspected by the municipal veterinarian on 9 August 2012 and samples from produce and the production environment were sent to the local environmental laboratory and analysed according to ISO 11290-1/A1-2004 standards. Meat jelly deliveries to institutions in other municipalities where outbreak cases had been identified were ascertained from the delivery lists of the production plant.

\section{Listeriosis surveillance and international outbreak inquiry}

Since 1995, the clinical microbiology laboratories in Finland are obliged to report L. monocytogenes findings isolated from blood, CSF, genital tract, newborn, deep puncture and surgical specimens to the NIDR and send the isolates to the Bacteriology Unit at THL for strain comparison. Clinicians notify the NIDR about culture-confirmed cases of invasive listeriosis. Food production plants are responsible for their own internal control activities. When local food laboratories detect $L$. monocytogenes during routine surveillance of food production plants these strains are sent to the microbiological laboratory of the Finnish Food Safety Authority Evira for serotyping and PFGE analysis. L. monocytogenes strains isolated from patients and from foods are serogrouped by PCR as described previously [11]. Pulsed-field gel electrophoresis (PFGE) with restriction enzyme $A s c \mathrm{I}$ (New England Biolabs, USA), standardized by PulseNet [12], were used to genotype the strains. The PFGE profiles were analysed using BioNumerics software v. 5.1 (Applied Maths, Belgium). In outbreak situations, PFGE profiles of patient and food strains are compared.

An international inquiry was conducted via the European Centre for Disease Prevention and Control (ECDC) in order to chart the incidence of the outbreak strain infection and possible sources in other European countries.

\section{Epidemiological investigation}

Clinical information was collected from patient records. Hospital outbreak cases were defined as patients present at or admitted to the municipal hospital in Vaasa in July 2012 with L. monocytogenes PFGE-type 225 isolated from blood or stool samples. Non-hospital outbreak cases were invasive listeriosis cases with L. monocytogenes PFGE-type 225 reported to the NIDR from other municipalities in Finland from June to August 2012.

By taking into account hospital ward admission dates in outbreak cases, symptom onset dates, and the incubation period for listerial gastroenteritis, the time-frame for possible exposure to the source of infection was determined.

We estimated the median incubation period for listerial gastroenteritis using the last date of serving suspected meat jelly in the ward before the beginning of the outbreak (18 July) and the time of onset of symptoms.

Local environmental health authorities collected information on deliveries of the suspected meat jelly to the institutional kitchens that provided meal services to cases of listeriosis reported to the NIDR from June to August 2012.

Two weeks after the beginning of the outbreak, patients still in the affected ward were administered a questionnaire regarding consumption of risk food items during their hospital stay and the same questionnaire was administered by phone to patients already discharged from the ward. Exact consumption dates for each food item were not enquired for. A case was defined as a patient treated on the ward in July 
2012 with laboratory-confirmed invasive or gastrointestinal listeriosis. From the data on exposure to the food items served to cases and non-cases, attack rates (AR, \%) and relative risks (RR) with 95\% confidence intervals (CI) for each exposure were calculated.

\section{RESULTS}

\section{Description of the hospital outbreak}

In July 2012, a total of ten cases infected with $L$. monocytogenes serogroup IIa PFGE-type 225 (Lm225) (currently reported by the ECDC molecular surveillance as PFGE-type AscI.0121) were identified at one ward of the municipal hospital of Vaasa (Table 1). The first two cases were diagnosed on 23 and 24 July, with Lm225 isolated from blood cultures. Of the 21 patients on the ward, 15 other patients provided samples for blood cultures due to fever or other septic symptoms, all of which were negative for $L$. monocytogenes. Thirteen of the patients had diarrhoea and provided stool samples; ten had the outbreak strain $L m 225$ in their stool samples.

The median incubation period for listerial gastroenteritis calculated from the exposure on 18 July was estimated to be $21 \mathrm{~h}$ (range 9-107) based on 9/10 cases diagnosed on the ward. It is a minimum estimate of the incubation period since the same meat jelly was probably served also on $11 \mathrm{July}$, and five patients may have been exposed twice. Taking into account the possibility of five patients being exposed already on 11 July, the median incubation period was $180 \mathrm{~h}$ (range 9-275). None of the cases had any underlying malignant disease but two were being treated with immunosuppressive agents (Table 1). The median age of the cases was 82 years (range 75-95); six were males. One case died 20 days after the onset of gastrointestinal listeriosis.

Two cases had stool cultures positive for Clostridium difficile (one of which was also positive for $C$. difficile toxin) and one case was PCR positive for adenovirus in faeces. No other gastrointestinal pathogens were found. No patients with fever or gastrointestinal illness of unknown aetiology were reported from the other wards of the hospital during the time-frame of the outbreak investigation (July and August 2012).

All patients with listerial gastroenteritis were treated with oral antibiotics (amoxicillin or alternatively trimethoprim-sulfamethoxazole if previously known to have a penicillin allergy) for a total of 10 days. Cases of invasive listeriosis were treated with intravenous antibiotics (ampicillin or trimethoprim-sulfamethoxazole) for a minimum period of 14 days depending on clinical recovery. Three patients with diarrhoeal symptoms were started on treatment with amoxicillin, which was discontinued when the absence of L. monocytogenes in their stool cultures was demonstrated.

\section{Traceback and environmental investigation}

The time-frame for exposure to the source of infection was determined to be between 13 and 18 July 2012 (Fig. 1). Among risk products identified from the hospital's menu cards, meat jelly was considered to be the most probable source of infection of $L$. monocytogenes since the other food items had been used also in other wards of the hospital (Table 2). Meat jelly was served at the breakfast buffet once per week on Wednesdays. On 7 July 2012, four packages of $1.5 \mathrm{~kg}$ each of readysliced meat jelly were delivered to the central kitchen of the municipal hospital. Three packages had a use-by date of 19 July 2012 and one of 23 July 2012. According to staff members, only approximately half of each package was consumed after opening due to the large size, and the remaining meat jelly was destroyed. Normally opened packages of perishable foodstuffs are destroyed if not consumed by the next day after opening. However, one staff member recalled that remaining meat jelly from a package opened and served to the patients on 11 July 2012 was stored in the refrigerator and could have been used on 18 July 2012. During the outbreak investigation, packages of meat jelly with a use-by date in July 2012 were no longer available for microbiological sampling, since neither the ward kitchen nor the central kitchen had any unopened packages in storage. However, samples were taken from seven packages of meat jelly from the same producer with use-by dates in August 2012. A total of 26 meal portions served between 13 and 18 July 2012 and 15 food items were sampled from the central kitchen of the municipal hospital. One food item (tubed ham) recovered also from the ward kitchen was tested although it was served on 19 July 2012, after the onset of the outbreak. Listeria was not found in any food or environmental samples taken from the municipal hospital.

The sliced meat jelly was produced at the production plant in $500 \mathrm{~kg}$ batches on a bi-weekly basis and delivered to customers across the entire country through a distribution company. The shelf life of the product was 19 days. At the production plant, internal 
Table 1. Clinical characteristics of all cases infected with Listeria monocytogenes serotype IIa PFGE-type 225, Finland, 2012

\begin{tabular}{|c|c|c|c|c|c|c|c|c|c|c|}
\hline Age & Sex & $\begin{array}{l}\text { Non-immune } \\
\text { underlying } \\
\text { conditions }\end{array}$ & $\begin{array}{l}\text { Underlying conditions } \\
\text { altering immune } \\
\text { system } \\
\text { (pharmacological } \\
\text { treatment of interest) }\end{array}$ & $\begin{array}{l}\text { Date of } \\
\text { onset } \\
\text { (day/ } \\
\text { month) }\end{array}$ & Symptoms & $\begin{array}{l}\text { Specimens } \\
\text { culture-positive for } \\
\text { L. monocytogenes } \\
\text { PFGE-type } 225\end{array}$ & $\begin{array}{l}\text { Specimens } \\
\text { culture-negative } \\
\text { for } L \text {. } \\
\text { monocytogenes }\end{array}$ & $\begin{array}{l}\text { Meat jelly served } \\
\text { at hospital ward } \\
\text { where patient has } \\
\text { been hospitalized } \\
\text { in the } 3 \text { weeks } \\
\text { before onset of } \\
\text { listeriosis }\end{array}$ & $\begin{array}{l}\text { Outcome } \\
\text { (death } \\
\text { occurred in } \\
\text { days after } \\
\text { onset of } \\
\text { illness) }\end{array}$ & $\begin{array}{l}\text { Incubation } \\
\text { time }(\mathrm{h})\end{array}$ \\
\hline \multicolumn{11}{|c|}{ Hospital outbreak cases } \\
\hline 87 & $\mathrm{~F}$ & $\begin{array}{l}\text { CHD, heart } \\
\text { insufficiency }\end{array}$ & & $18 / 7$ & $\begin{array}{l}\text { Fever, } \\
\text { diarrhoea }\end{array}$ & Blood, stool & & Yes & Alive & 9 \\
\hline 82 & $\mathrm{M}$ & $\begin{array}{l}\text { Hypertension, } \\
\text { dementia }\end{array}$ & & $18 / 7$ & $\begin{array}{l}\text { Fever, } \\
\text { CNS }\end{array}$ & Stool & Blood, CSF & Yes & Alive & 10 \\
\hline 82 & M & $\begin{array}{l}\text { Epilepsy, AF, } \\
\text { hypertension, } \\
\text { stroke }\end{array}$ & & $18 / 7$ & $\begin{array}{l}\text { Fever, } \\
\text { diarrhoea }\end{array}$ & Stool & Blood & Yes & Alive & 12 \\
\hline 82 & $\mathrm{~F}$ & $\begin{array}{l}\text { Osteoporosis, RA } \\
\text { (no steroids) }\end{array}$ & & $19 / 7$ & $\begin{array}{l}\text { Fever, } \\
\text { diarrhoea }\end{array}$ & Blood, stool & & Yes & Alive & 33 \\
\hline 82 & M & $\begin{array}{l}\text { DM2, } \\
\text { hypertension, } \\
\text { heart } \\
\text { insufficiency, } \\
\text { Alzheimer's } \\
\text { disease }\end{array}$ & & $19 / 7$ & $\begin{array}{l}\text { Fever, } \\
\text { diarrhoea }\end{array}$ & Stool & Blood & Yes & Alive & 21 \\
\hline 75 & M & ASO, DM2 & $\begin{array}{l}\text { Ulcerative colitis } \\
\text { (sulfasalazine) }\end{array}$ & $20 / 7$ & Diarrhoea & Stool & Blood & Yes & Alive & 50 \\
\hline 78 & $\mathrm{~F}$ & $\begin{array}{l}\mathrm{AF}, \mathrm{DM} 2 \text {, heart } \\
\text { insufficiency }\end{array}$ & $\begin{array}{l}\text { Lung sarcoidosis } \\
\text { (steroids) }\end{array}$ & $20 / 7$ & $\begin{array}{l}\text { Fever, } \\
\text { diarrhoea }\end{array}$ & Stool & Blood & Yes & Dead (20) & 43 \\
\hline 95 & $\mathrm{~F}$ & Pyelonephritis & & $21 / 7$ & Diarrhoea & Stool & Blood & Yes & Alive & 75 \\
\hline 86 & $\mathrm{M}$ & $\begin{array}{l}\text { COPD, } \\
\text { hypertension, } \\
\text { CHD, } \\
\text { Clostridum } \\
\text { difficile enteritis }\end{array}$ & & & Diarrhoea & Stool & Blood & Yes & Alive & n.d. \\
\hline 88 & M & $\begin{array}{l}\text { CHD, } \\
\text { osteoporosis }\end{array}$ & & $22 / 7$ & Fever & Stool & Blood & Yes & Alive & 107 \\
\hline \multicolumn{11}{|c|}{ Non-hospital } \\
\hline 91 & $\mathrm{M}$ & $\begin{array}{l}\text { AF, hypertension, } \\
\text { WPW }\end{array}$ & & $18 / 6$ & Fever & Blood & n.d. & n.d. & Alive & n.d. \\
\hline 72 & $\mathrm{~F}$ & $\begin{array}{c}\text { Chronic renal } \\
\text { insufficiency }\end{array}$ & $\begin{array}{l}\text { Heart transplant } \\
\text { recipient }\end{array}$ & $23 / 6$ & Fever & Blood & n.d. & Yes & Alive & n.d. \\
\hline
\end{tabular}




\begin{tabular}{|c|c|c|c|c|c|c|c|c|c|c|}
\hline Age & Sex & $\begin{array}{l}\text { Non-immune } \\
\text { underlying } \\
\text { conditions }\end{array}$ & $\begin{array}{l}\text { Underlying conditions } \\
\text { altering immune } \\
\text { system } \\
\text { (pharmacological } \\
\text { treatment of interest) }\end{array}$ & $\begin{array}{l}\text { Date of } \\
\text { onset } \\
\text { (day/ } \\
\text { month) }\end{array}$ & Symptoms & $\begin{array}{l}\text { Specimens } \\
\text { culture-positive for } \\
\text { L. monocytogenes } \\
\text { PFGE-type } 225\end{array}$ & $\begin{array}{l}\text { Specimens } \\
\text { culture-negative } \\
\text { for } L \text {. } \\
\text { monocytogenes }\end{array}$ & $\begin{array}{l}\text { Meat jelly served } \\
\text { at hospital ward } \\
\text { where patient has } \\
\text { been hospitalized } \\
\text { in the } 3 \text { weeks } \\
\text { before onset of } \\
\text { listeriosis }\end{array}$ & $\begin{array}{l}\text { Outcome } \\
\text { (death } \\
\text { occurred in } \\
\text { days after } \\
\text { onset of } \\
\text { illness) }\end{array}$ & $\begin{array}{l}\text { Incubation } \\
\text { time (h) }\end{array}$ \\
\hline 90 & M & $\begin{array}{l}\text { Alzheimer, } \\
\text { diabetes, } \\
\text { hypertension }\end{array}$ & & $9 / 7$ & Jaundice & Blood & n.d. & Yes & Alive & n.d. \\
\hline 72 & $\mathrm{~F}$ & CHD DM & Vasculitis (steroids) & $13 / 7$ & Fever & Blood & n.d. & Yes & Dead (4) & n.d. \\
\hline 80 & M & $\begin{array}{l}\text { Alzheimer's, } \\
\text { DM2, chronic } \\
\text { renal } \\
\text { insufficiency }\end{array}$ & $\begin{array}{l}\text { Rectal } \\
\text { adenocarcinoma }\end{array}$ & $26 / 7$ & Fever & Blood & n.d. & Yes & Alive & n.d. \\
\hline 80 & $\mathrm{~F}$ & $\begin{array}{l}\text { Hypertension, } \\
\text { CHD }\end{array}$ & ITP (steroids) & $31 / 7$ & Fever & Blood & n.d. & Yes & Alive & n.d. \\
\hline 57 & M & $\begin{array}{l}\text { Asthma, } \\
\text { hypertension }\end{array}$ & Cerebral glioma & $5 / 8$ & Fever & Blood, CSF & n.d. & Yes & Alive & n.d. \\
\hline 62 & M & & $\begin{array}{l}\text { Rectal } \\
\text { adenocarcinoma }\end{array}$ & $12 / 8$ & Fever & Blood & n.d. & n.d. & Alive & n.d. \\
\hline 62 & $\mathrm{~F}$ & $\begin{array}{l}\text { Hypertension, } \\
\text { asthma }\end{array}$ & Myelofibrosis & $23 / 8$ & $\begin{array}{r}\text { Fever, } \\
\text { CNS }\end{array}$ & Blood & n.d. & n.d. & Dead (5) & n.d. \\
\hline 73 & M & Hydrocephalus & $\begin{array}{l}\text { Kidney transplant } \\
\text { recipient }\end{array}$ & $27 / 8$ & $\begin{array}{r}\text { Fever, } \\
\text { CNS }\end{array}$ & $\mathrm{CSF}$ & n.d. & Yes & Alive & n.d. \\
\hline
\end{tabular}

CHD, Coronary heart disease; AF, atrial fibrillation; CNS, central nervous system involvement; CSF, cerebrospinal fluid; ITP, idiopathic thrombocytopenic purpura; DM2, diabetes mellitus type 2; ASO, arteriosclerosis obliterans; COPD, chronic obstructive pulmonary disease; RA, rheumatoid arthritis; WPW, Wolff-Parkinson-White syndrome; M, male; F, memale; n.d., No data. 


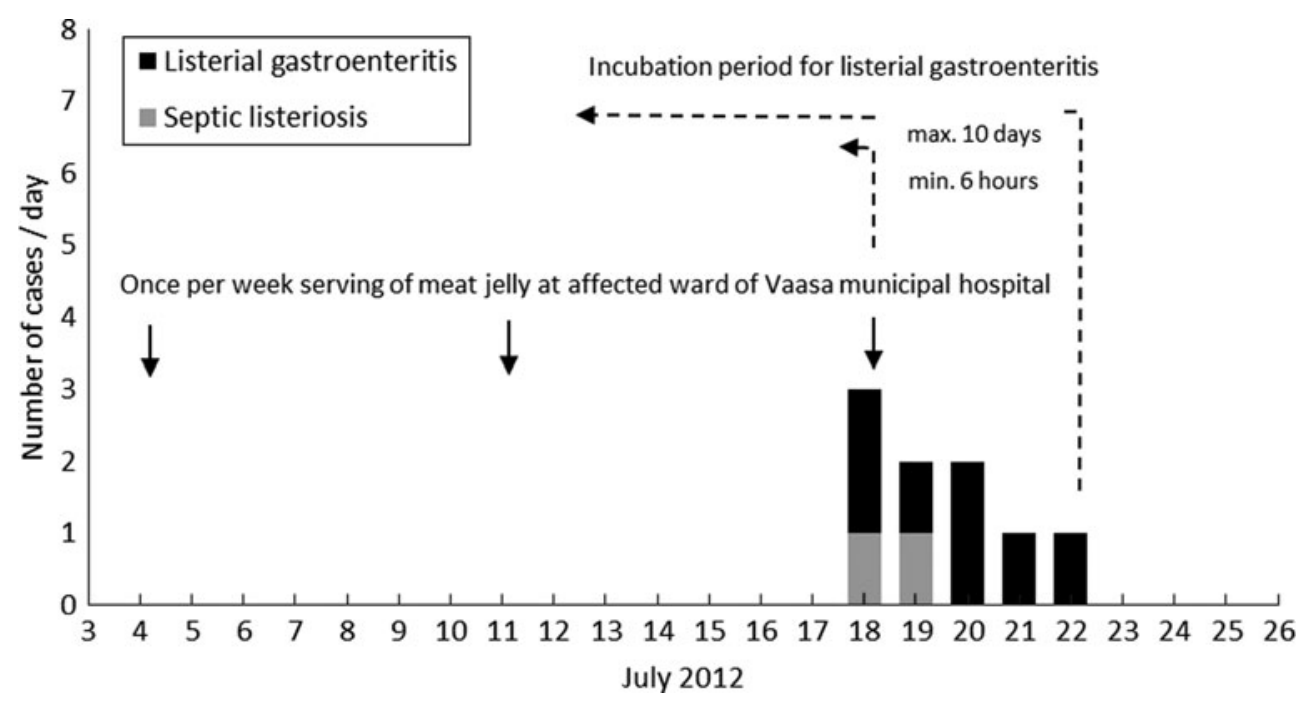

Fig. 1. Hospital outbreak cases $(n=9)$ of Listeria monocytogenes serotype IIa, PFGE-type 225, Vaasa Central Hospital, Finland July 2012, by date of onset of symptoms.

quality sampling from produce and the production environment had yielded negative results for Listeria from March to May 2012 but in February 2012, L. monocytogenes that was different from the outbreak strain was detected in another meat product. A pooled sample taken on 9 August 2012 from a floor drain and a trolley wheel in the food processing environment was positive for $L m 225$. During the same environmental investigation, a non-outbreak strain of L. monocytogenes was recovered from the slicing machine. The L. monocytogenes strains detected in another meat product and from the slicing machine were clearly different from the outbreak strain.

\section{National surveillance and epidemiological investigation}

Between 18 June and 23 August 2012, ten additional cases with $L m 225$ were reported to the NIDR from ten other municipalities across Finland (Table 1). Their median age was 73 years (range 57-91) and six were males. L. monocytogenes was isolated from blood in nine cases and from CSF in one case. In their medical records, presence of diarrhoea or stool testing for Listeria was not mentioned. Nine cases had underlying conditions associated with higher risk for invasive listeriosis. Two cases died within 4 and 5 days after onset of illness. Eight had been in institutional care during June and July 2012. Meat jelly had been served in seven of these care facilities, and based on delivery lists, six facilities received ready-sliced meat jelly from the same processing facility that also delivered meat jelly to the municipal hospital in Vaasa.
Between June and August 2012, in parallel with the 20 cases caused by the outbreak strain $\operatorname{Lm} 225$, nine cases of invasive listeriosis caused by nine distinct non-outbreak strains of $L$. monocytogenes were notified to the NIDR. Six cases had been in institutional care before the onset of listeriosis and in five of these care facilities, meat jelly had not been served; in one facility, information was not available.

Thirteen out of 21 patients present on the ward of the municipal hospital in Vaasa at the time of the outbreak answered the questionnaire regarding consumption of risk food items (one patient could not answer because of cognitive impairment, three patients had died and four declined to participate); none of the food items included in the questionnaire was significantly associated with listeriosis (Table 3).

The inquiry via the ECDC revealed that the case numbers of listeriosis had not increased in the six European countries that responded. Three countries that used PFGE-typing reported that $L m 225$ was a rare genotype.

\section{DISCUSSION}

In July 2012, an outbreak including 10 Lm225 cases occurred in a municipal hospital in Finland causing listerial gastroenteritis and septic listeriosis. The same Listeria strain caused invasive listeriosis in ten cases in other municipalities across Finland in the period June to August 2012. Our investigation found meat jelly to be the probable source of infection for the 20 listeriosis cases. Meat jelly was the only food 
Table 2. Traceback investigations of food items served in the week preceding the outbreak of $\mathrm{L}$. monocytogenes; samples recovered from the central kitchen of the municipal hospital in Vaasa, Finland 2012

\begin{tabular}{|c|c|c|c|}
\hline Date of serving & Food item & Detection of L. monocytogenes & Comment or reason why not sent for culture \\
\hline \multirow[t]{6}{*}{13 July } & Pork and bacon & Neg. & Frozen sample \\
\hline & Potatoes & Neg. & Frozen sample \\
\hline & Warm vegetables & Neg. & Frozen sample \\
\hline & Salad & n.d. & Possible risk item but widespread use in hospital \\
\hline & Raspberry cream & n.d. & Served heated \\
\hline & Vegetable soup & n.d. & Served heated \\
\hline \multirow[t]{8}{*}{14 July } & Chicken filet & Neg. & Frozen sample \\
\hline & Curry sauce & Neg. & Frozen sample \\
\hline & Potatoes & Neg. & Frozen sample \\
\hline & Warm vegetables & Neg. & Frozen sample \\
\hline & Fruit salad & Neg. & Frozen sample \\
\hline & Multigrain porridge & n.d. & Served heated \\
\hline & Fruit soup & n.d. & Closed container from producer \\
\hline & Cold-cut meats & n.d. & Possible risk item but widespread use in hospital, small packages \\
\hline \multirow{8}{*}{15 July } & Meat stew & Neg. & Frozen sample \\
\hline & Root vegetable purée & Neg. & Frozen sample \\
\hline & Salad & Neg. & Frozen sample \\
\hline & Cranberry cream & n.d. & Served heated \\
\hline & Whipped cream & n.d. & Possible risk item but widespread use in hospital \\
\hline & Semolina porridge & n.d. & Served heated \\
\hline & Fruit jam & n.d. & Not considered risk product \\
\hline & Cheese & n.d. & Possible risk item but widespread use in hospital, small packages \\
\hline \multirow[t]{6}{*}{16 July } & Dill stewed meat & Neg. & Frozen sample \\
\hline & Potatoes & Neg. & Frozen sample \\
\hline & Warm vegetables & Neg. & Frozen sample \\
\hline & Salad & Neg. & Frozen sample \\
\hline & Pear and banana cream & n.d. & Served heated \\
\hline & Fish soup & n.d. & Served heated \\
\hline \multirow[t]{6}{*}{17 July } & Minced meat and potato casserole & Neg. & Frozen sample \\
\hline & Fruit jam & n.d. & Not considered risk product \\
\hline & Salad & Neg. & Frozen sample \\
\hline & Apricot cream & n.d. & Served heated \\
\hline & Spinach soup & n.d. & Served heated \\
\hline & Eggs & n.d. & Served heated \\
\hline \multirow[t]{6}{*}{18 July } & Meat soup & n.d. & Served heated \\
\hline & Semolina porridge & Neg. & Frozen sample \\
\hline & Berry soup & Neg. & Frozen sample \\
\hline & Vegetable gratin & Neg. & Frozen sample \\
\hline & Cold-cut meats & n.d. & Possible risk item but widespread use in hospital, small packages \\
\hline & Salad & Neg. & Frozen sample \\
\hline
\end{tabular}




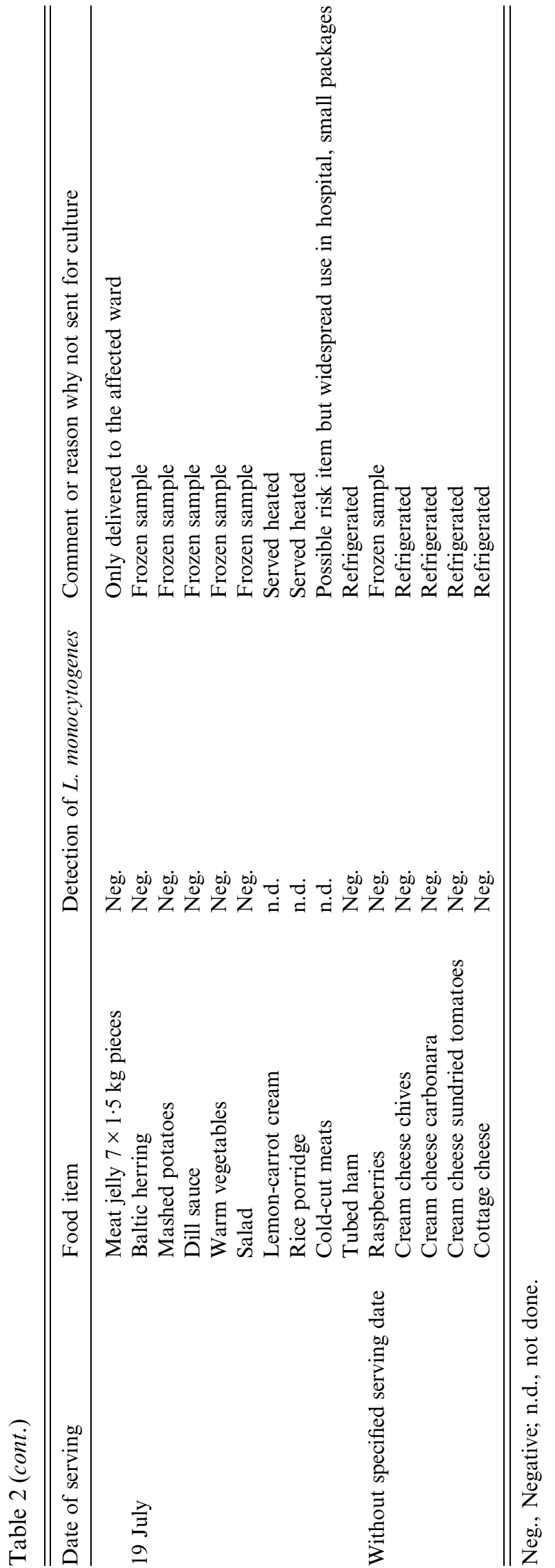

item that was served solely at the affected ward of the hospital during the exposure period, while no other wards within the same hospital reported any cases of listeriosis. Also a large proportion of non-hospital outbreak cases had a possibility to be exposed to meat jelly from the same producer as in the hospital outbreak cases. $\operatorname{Lm} 225$ is a rare genotype but was found at the meat jelly processing environment; after the producer voluntarily stopped the production of meat jelly in August 2012, no additional cases of Lm225 were notified to the NIDR. However, Listeria could not be found in any of the available samples of meat jelly tested and the questionnaire study in the hospital outbreak setting did not find a statistical association between meat jelly consumption and listeriosis.

In the hospital outbreak, both blood and stool samples from all symptomatic patients were tested for $L$. monocytogenes. Listeria infection was limited to the gastrointestinal tract in eight out of ten of the hospital outbreak cases. In contrast, all $L m 225$ cases reported from other municipalities occurred as invasive disease. These cases were younger than hospital outbreak cases but had underlying conditions altering their immune systems. Most of the hospital outbreak cases did not have any underlying condition other than high age, which is typically associated with increased risk of acquiring invasive listeriosis [1]. The median incubation time of $21 \mathrm{~h}$ in our study corresponds with incubation times reported in other outbreaks of listerial gastroenteritis while the minimum estimated incubation period of $9 \mathrm{~h}$ for one patient with invasive listeriosis is short compared to the literature [5]. This patient was admitted to the ward on 13 July, between weekly meat jelly servings on 11 and 18 July. Fever was a presenting symptom along with diarrhoea in many of these cases and has been described as a frequent symptom in other outbreaks of listerial gastroenteritis [6, 13-15], although absence of invasive disease has not always been fully ascertained. Antibiotic treatment for listerial gastroenteritis was provided in accordance with suggestions from previous publications [2, 3, 14] and was regarded as a safety measure due to the high age of the patients in this outbreak [1].

Early in the outbreak investigation, it became evident that only one of 13 wards at the municipal hospital reported cases of listeriosis. Analysis of meal cards and food supplies from the central kitchen of the hospital showed that while food items typically associated with listerial contamination such as cold cut meats and soft cheese were in widespread use 
Table 3. Analytical study of exposure to diverse food items in patients hospitalized in the affected ward during outbreak and available for questionnaire $(n=13)$, Vaasa, Finland, July 2012

\begin{tabular}{|c|c|c|c|c|c|c|c|c|c|}
\hline \multirow[b]{2}{*}{ Exposure } & \multicolumn{3}{|c|}{ Exposed } & \multicolumn{3}{|c|}{ Unexposed } & \multirow[b]{2}{*}{$\mathrm{RR}$} & \multirow[b]{2}{*}{$95 \% \mathrm{CI}$} & \multirow[b]{2}{*}{$P$} \\
\hline & Total & Cases* & $\mathrm{AR} \%$ & Total & Cases* & $\mathrm{AR} \%$ & & & \\
\hline Cold-cut meats & 10 & 8 & $80 \cdot 00$ & 1 & 0 & 0 & - & - & 0.087 \\
\hline Sausage & 7 & 6 & $85 \cdot 71$ & 3 & 1 & $33 \cdot 33$ & $2 \cdot 57$ & $0 \cdot 50-13 \cdot 11$ & $0 \cdot 098$ \\
\hline Meat jelly & 7 & 6 & $85 \cdot 71$ & 4 & 2 & $50 \cdot 00$ & $1 \cdot 71$ & $0 \cdot 61-4 \cdot 78$ & $0 \cdot 201$ \\
\hline Tubed ham & 3 & 3 & $100 \cdot 00$ & 6 & 4 & $66 \cdot 67$ & $1 \cdot 50$ & $0 \cdot 85-2 \cdot 64$ & $0 \cdot 257$ \\
\hline Liver sausage & 9 & 7 & $77 \cdot 78$ & 2 & 1 & $50 \cdot 00$ & $1 \cdot 56$ & $0 \cdot 37-6 \cdot 50$ & $0 \cdot 425$ \\
\hline Butter & 4 & 3 & $75 \cdot 00$ & 7 & 4 & $57 \cdot 14$ & $1 \cdot 31$ & $0 \cdot 56-3 \cdot 09$ & $0 \cdot 554$ \\
\hline Milk & 10 & 7 & $70 \cdot 00$ & 2 & 1 & $50 \cdot 00$ & $1 \cdot 40$ & $0 \cdot 33-5 \cdot 93$ & $0 \cdot 584$ \\
\hline Cream & 2 & 1 & $50 \cdot 00$ & 10 & 7 & $70 \cdot 00$ & $0 \cdot 71$ & $0 \cdot 17-3 \cdot 03$ & $0 \cdot 584$ \\
\hline Cheese & 9 & 6 & $66 \cdot 67$ & 3 & 2 & $66 \cdot 67$ & $1 \cdot 00$ & $0 \cdot 40-2 \cdot 52$ & $1 \cdot 000$ \\
\hline Margarine & 12 & 8 & $66 \cdot 67$ & 0 & 0 & 0 & - & - & . \\
\hline
\end{tabular}

$\mathrm{AR}$, attack rate; RR, Relative risk; CI, Confidence interval.

* Culture positive in blood and/or stool for outbreak strain of L. monocytogenes.

across the hospital, only the ward with listeriosis cases ordered and served ready-sliced meat jelly on a weekly basis. Keeping in mind that the first case was diagnosed on 23 July, it was noted that five cases were present on the ward only during the meat jelly serving on 18 July and one of the cases was admitted on 17 July, helping to delimit the exposure period. Despite thorough food and environmental testing, Listeria was not found in any of the samples tested. However, samples of meat jelly that was served to the patients were no longer available for testing.

The central kitchen of the municipal hospital in Vaasa is an object for regular control from the municipal food safety authority, based on national and local regulations [16]. In 2010, THL and Food Safety Authority Evira issued a notice to the institutional kitchens in order to remind the food safety authorities and professionals about listeriosis and food products considered risky. However, no comprehensive national guidelines for minimizing listeriosis risk in hospitals or care facilities exist in Finland. Considering the severe outcome of listeriosis, guidelines should be developed for food serving in hospitals and long-term care facilities.

Meat jelly contains more water than other meat products, creating a good environment for growth of Listeria and slicing of the produce at the production plant increases surfaces exposed to Listeria from the production environment. In the municipal hospital, it was possible that an opened meat jelly package was stored in the refrigerator for a whole week between serving and the amount of bacteria in the produce may have increased to a level above the threshold of 100 c.f.u./g allowed in finished food products according to European regulations [17]. In a study describing the prevalence of $L$. monocytogenes in ready-to-eat foods, levels exceeding 100 c.f.u./g were not found during the shelf life of heat-treated meat products, but low frequencies of samples exceeding the allowed limit of 100 c.f.u./g were observed for fish and cheese products, at $0 \cdot 5 \%$ and $0 \cdot 2 \%$, respectively [18]. In previously described outbreaks of listerial gastroenteritis, estimates of the density of $L$. monocytogenes in source products have ranged from $3 \times 10^{1}$ c.f.u./g to $1.6 \times 10^{9}$ c.f.u./g $[19,20]$. Further, in outbreaks of invasive listeriosis, the bacterial density in incriminated food products have varied substantially from $<100$ c.f.u./g in most samples of butter recovered in a very large hospital-related outbreak [7] to $6 \times 10^{6}$ c.f.u./g in a hospital-related outbreak caused by contaminated cheese in Norway [21].

According to national and European surveillance data, the outbreak strain in our study, Lm225, was a rare PFGE type. At the meat jelly processing plant, Lm225 was detected from one sample in the production environment and also a non-outbreak strain of L. monocytogenes was recovered from the meat slicing machine. Our experiences in this and a previous study [22] suggest that the regulatory limit of 100 c.f.u./g might cause confusion at the production plant and among the authorities dictating control measures, since low levels of Listeria are allowed in the products at retail level. Furthermore, our findings suggest that L. monocytogenes should be kept in mind as a causal 
agent in foodborne outbreaks with febrile gastroenteritis with a short incubation period, while national guidelines on stool testing should be updated accordingly. Blood cultures are rarely available outside of institutional care or hospital settings to serve as a listeriosis outbreak detection signal.

\section{ACKNOWLEDGEMENTS}

We thank the patients and personnel of the municipal hospital in Vaasa for their collaboration and efforts in answering questionnaires and compiling clinical data. We thank the infectious diseases officers and local authorities who conducted additional investigations regarding food supplies to their respective institutions. We thank the personnel in the Evira and THL laboratories and the epidemiology unit for their skilful assistance. We also thank Merja Rautio from the Helsinki Central Hospital Laboratory (HUSLAB) for valuable comments on stool testing for L. monocytogenes.

\section{DECLARATION OF INTEREST}

None.

\section{REFERENCES}

1. Goulet $\mathrm{V}$, et al. Incidence of listeriosis and related mortality among groups at risk of acquiring listeriosis. Clinical Infectious Diseases 2012; 54: 652-660.

2. Allerberger $\mathbf{F}$, Wagner M. Listeriosis: a resurgent foodborne infection. Clinical Microbiology and Infection 2010; 16: 16-23.

3. Ooi ST, Lorber B. Gastroenteritis due to Listeria monocytogenes. Clinical Infectious Diseases 2005; 40: 1327-1332.

4. Barbuddhe SB, Chakraborty T. Listeria as an enteroinvasive gastrointestinal pathogen. Current Topics in Microbiology and Immunology 2009; 337: 173-195.

5. Goulet $\mathbf{V}$, et al. What is the incubation period for listeriosis? BMC Infectious Diseases 2013; 13: 11.

6. Miettinen MK, et al. Molecular epidemiology of an outbreak of febrile gastroenteritis caused by Listeria monocytogenes in cold-smoked rainbow trout. Journal of Clinical Microbiology 1999; 37: 2358-2360.

7. Lyytikäinen $\mathbf{O}$, et al. An outbreak of Listeria monocytogenes serotype $3 \mathrm{a}$ infections from butter in Finland. Journal of Infectious Diseases 2000; 181: 1838-1841.

8. Niskanen T, et al. (eds). Food borne and water borne outbreaks in Finland 2006 [in Finnish] (http://www.evira.
fi/portal/fi/tietoa+evirasta/julkaisut/?a=view\&productId= 182). Accessed 2 March 2015.

9. Jaakola S, et al. (eds). Infectious diseases in Finland 2011. (http://urn.fi/URN:ISBN:978-952-245-662-5). Accessed 2 March 2015.

10. Cokes C, et al. Serving high-risk foods in a high-risk setting: survey of hospital food service practices after an outbreak of listeriosis in a hospital. Infection Control and Hospital Epidemiology 2011; 32: 380-386.

11. Doumith M, et al. Differentiation of the major Listeria monocytogenes serovars by multiplex PCR. Journal of Clinical Microbiology 2004; 42: 3819-3822.

12. Graves LM, Swaminathan B. PulseNet standardized protocol for subtyping Listeria monocytogenes by macrorestriction and pulsed-field gel electrophoresis. International Journal of Food Microbiology 2001; 65: $55-62$.

13. Dalton CB, et al. An outbreak of gastroenteritis and fever due to Listeria monocytogenes in milk. New England Journal of Medicine 1997; 336: 100-105.

14. Pichler $\mathbf{J}$, et al. An outbreak of febrile gastroenteritis associated with jellied pork contaminated with Listeria monocytogenes. Wiener klinische Wochenschrift 2009; 121: 149-156.

15. Aureli $\mathbf{P}$, et al. An outbreak of febrile gastroenteritis associated with corn contaminated by Listeria monocytogenes. New England Journal of Medicine 2000; 342: 1236-1241.

16. Ministry of Agriculture and Forestry, Finland. Food Act 23/2006 (http://www.finlex.fi/en/laki/kaannokset/2006/ en20060023.pdf). Accessed 2 March 2015.

17. Commission of the European Communities. Commission Regulation (EC) No 2073/2005 of 15 November 2005 on microbiological criteria for foodstuffs (http://eurlex. europa.eu/LexUriServ/LexUriServ.do?uri=OJ:L:2005:338: 0001:0026:EN:PDF). Accessed 2 March 2015.

18. Lambertz ST, et al. Prevalence and level of Listeria monocytogenes in ready-to-eat foods in Sweden 2010. International Journal of Food Microbiology 2012; 160: 24-31.

19. Carrique-Mas JJ, et al. Febrile gastroenteritis after eating on-farm manufactured fresh cheese - an outbreak of listeriosis? Epidemiology and Infection 2003; 130: 79-86.

20. Frye DM, et al. An outbreak of febrile gastroenteritis associated with delicatessen meat contaminated with Listeria monocytogenes. Clinical Infectious Diseases 2002; 35: 943-949.

21. Johnsen BO, et al. A large outbreak of Listeria monocytogenes infection with short incubation period in a tertiary care hospital. Journal of Infection 2010; 61: 465-470.

22. Nakari UM, et al. Investigation of increased listeriosis revealed two fishery production plants with persistent Listeria contamination in Finland in 2010. Epidemiology and Infection 2014; 142: 2261-2269. 